\title{
The practice of dentistry amidst the COVID-19 pandemic
}

\author{
Kaitlyn Dal Molin ${ }^{1} \cdot$ Christian Loo $^{1} \cdot$ Reza B. Kazemi ${ }^{1} \cdot$ Geraldine Weinstein $^{2}(\mathbb{C}$ \\ Received: 9 June 2020 / Accepted: 23 December 2020 / Published online: 4 February 2021 \\ (๑) The Author(s), under exclusive licence to Springer Nature Switzerland AG part of Springer Nature 2021
}

\begin{abstract}
The initial onset of the novel coronavirus, COVID-19, in humans was first reported in Wuhan, China, in December 2019. Due to rapidly spreading the COVID-19 outbreak worldwide, the World Health Organization declared a pandemic on March 11th, 2020 that has globally increased to $62,844,837$ cases worldwide with a total of 1,465,144 confirmed deaths, as of December 1st, 2020. With the ever-evolving nature of COVID-19, it is imperative that healthcare professionals, especially those in the dental profession, remain educated and prepared with the best inclusive practices to ensure the safety of their patients, staff, and themselves. A review of guidelines from organizations around the world has been conducted to evaluate the most comprehensive strategies dental practices can take to minimize the risk of disease transmission during the pandemic and the post-pandemic future.
\end{abstract}

Keywords COVID-19 · Personal protective equipment · Infectious disease · Emergency protocols · Urgency $\cdot$ Non-urgent/elective

\section{Quick reference/description}

COVID-19, a novel coronavirus, was first reported in Wuhan, China in December 2019. It has since spread rapidly across all continents except Antarctica. As of December 1st, 2020, the World Health Organization (WHO), reports cases of COVID-19 have been confirmed in 235 countries and territories, causing 62,844,837 confirmed cases and 1,465,144 confirmed deaths.

About $80 \%$ of cases present with mild to no symptoms, which increases both the rate of undiagnosed cases and the spread of COVID-19. The virus is most transmissible when patients are most symptomatic, however, the transmission of the virus can occur prior to the presentation of any symptoms. According to Ather et al., the transmission has been shown to occur through aerosol

\section{Geraldine Weinstein}

gmwein@upenn.edu

1 University of Connecticut School of Dental Medicine, Farmington, USA

2 University of Pennsylvania School of Dental Medicine, Philadelphia, USA 
production, fomites, or fecal-oral transmission. Research from Hoffmann et al. has shown that COVID-19 binds to human ACE 2 positive cells, which present in high concentrations in salivary glands. The Center for Disease Control (CDC) recommends keeping at least a 6-foot distance from others due to the radius that the virus can be spread through coughing or sneezing. The virus has been found to be viable for up to 9 days on hard surfaces, such as plastics or metals.

Dental professionals are at a high risk of contracting nosocomial infections due to the unique nature of dental procedures which causes aerosolized saliva. Proper use of personal protective equipment (PPE) is essential in preventing the spread of COVID-19 to dental healthcare workers. This is especially important when the patient is possibly an asymptomatic carrier of COVID-19. Until a vaccine or cure for COVID-19 is implemented, fastidious protocols are essential in the dental office to prevent spread of the virus.

\section{Symptoms}

Symptoms for COVID-19 patients may appear 2-14 days after exposure and can range from mild, flu-like symptoms to pneumonia, multiple organ failure, and acute respiratory distress. The outlier incubation period of the virus has been reported from up to 24-27 days.

Clinical manifestations for COVID-19 patients include

- Fever

- Dry cough

- Shortness of breath

- Chills

- Repeated shaking with chills

- Muscle pain

- Headache

- Sore throat

- Possible loss of taste or smell

Other symptoms of COVID-19 may include

- Lethargy

- Diarrhea

- Nausea

- Vomiting

- Abnormal chest X-ray: ground glass appearance

- Acute respiratory distress

- Loss of taste/smell

- Red-purple, tender or itchy bumps developing mostly on the toes, can also be present on heels or fingers (COVID Toes) 


\section{Clinical examination}

During COVID-19 Pandemic, it is necessary to minimize patient visits. The following is a compilation of recommendations for care of patients during this difficult time.

Dental health care personnel (DHCP) and dental setting preparations from the American Dental Association (ADA) and CDC: Staff preparations:

- Flu vaccine for all DHCP

- DHCP with symptoms of COVID-19 or influenza should not report to work but should self-isolate.

- DHCP at high risk of contracting COVID-19 (people above the age of 65, with pre-existing conditions or medically compromised, pregnancy, etc.).

- DHCP should self-monitor for respiratory symptoms and check temperature twice a day.

- Convalescent DHCP assigned to care for known or suspected COVID-19 patients.

- Conduct inventory of available PPE.

- Establish updated infection control protocol with responsible staff members to be applied after each patient.

Office preparations:

- A hand sanitization station should be available at the entrance, with a notice of mandatory mask requirement in the office. Other patient education material may also be placed throughout the office. Hand hygiene notices may also help patients and staff apply proper hygiene at required times and places.

- Supplies (tissues, alcohol-based hand sanitizer, trash cans) should be readily available to facilitate maintenance and hygiene of common spaces.

- Installation of the clear barrier for the front desk. Alternatively, front desk staff may wear face shields, in addition to face masks.

- Encourage physical distancing by arranging seating in waiting rooms and employee spaces so patients and employees can sit at least 6 feet apart. Also, consider outdoor spaces seating for staff breaks.

- Remove objects that are difficult to disinfect such as magazines, toys, excess/surplus furniture, and other objects that may be touched by others from waiting and office areas.

- When applicable, replace high-touch communal items with pre-packaged, singleserving items (e.g. bottled water, pre-packaged snacks), and high-touch surfaces with no-touch alternatives (e.g. faucets, soap, hand sanitizer)

- Request staff to wipe down contact areas routinely after use.

- Separate staff from patient bathroom

Scheduling considerations: 
- When scheduling patients, inform them that only patients will be allowed in the waiting area. Only patients that require caregivers (children, mentally or physically disabled, elderly, and patients who need an interpreter) will be allowed a companion to the appointment.

- Establish a template for scheduling patients to allow for social distancing by eliminating waiting time in the office. Employee scheduling should also maximize distancing by reducing number of employees using the same office spaces at any given time.

\section{Remote prescription recommendations and key principles from the United Kingdom General Dental Council:}

- Make patient safety the first priority.

- Understand how to identify vulnerable patients and take appropriate steps to protect them.

- Establish a dialogue and make sure the patient understands how the remote consultation is going to work.

- Explain that:

- The dental provider can only prescribe if it is safe to do so.

- Sufficient information about the patient's health is necessary prior to prescribing.

- It may be unsafe if relevant information is not shared with other healthcare providers involved in their care.

- Remote care may be unsuitable to meet all patient's needs.

- Provide patients with all the options available to them, including declining treatment, in a way they can understand.

- Make appropriate arrangements for aftercare and, unless the patient objects, share all relevant information with colleagues and other health and social care providers involved in their care to support ongoing monitoring and treatment.

- Keep notes that fully explain and justify the decisions they make.

- Stay up to date with relevant training, support and guidance for providing healthcare in a remote context.

\section{COVID-19 and pain control in dentistry}

The French Minister of Solidarity and Health, Oliver Veran, released a statement in early March suggesting that the use of Ibuprofen, and other such NSAIDs, should be avoided in COVID-19 positive patients due to the potential of worsening or prolonging the infection. This advice follows an article published on March 11th, 2020 in the Lancet medical journal, where it was hypothesized that NSAIDs increase angiotensin-converting enzyme 2 (ACE-2) and can lead to an aggravation of COVID-19 symptoms. The rise in concern is due to COVID-19's mechanism of action. Coronavirus targets cells of the lungs, intestines, kidneys, and blood vessels by binding to these target cells through ACE-2 receptors. Ibuprofen increases the expression of 
ACE-2. The Lancet hypothesized that this increase in ACE-2 could exacerbate the symptoms of COVID-19.

On March 19th, 2020, the WHO rescinded their previous statement and currently does not recommend avoiding Ibuprofen for treatment of COVID-19 due to a lack of scientific evidence. Concurrently, the United States Food and Drug Administration (FDA) also believes that there is not enough scientific evidence to support that Ibuprofen will increase the severity of COVID-19 symptoms. However, the UK National Health Service (NHS) and the BMJ journal, both recommend against it even though there is no strong evidence of a connection between ibuprofen and an exacerbation of COVID-19 symptoms, it is best to take paracetamol to manage symptoms of COVID-19 until further research can be conducted.

\section{Screening, and telecommunication options}

The ADA has put out a statement regarding interim guidance to minimize the exposure of COVID-19 while managing emergent and urgent dental care needs. The ADA makes it apparent that these algorithms are a guide to help dental providers minimize the risk and exposure of COVID-19 and are not directives.

\section{- Telecommunication: Algorithm 1-triage:}

- Speak to the patient over the phone or through video conference to determine the urgency for a dental visit.

- Ensure that the provider has informed consent from the patient to triage on the phone.

- Postpone elective procedures and concentrate efforts on managing dental emergencies.

- Remote consultations and prescribing can be used to manage emergencies.

\section{- Patient interview and assessment: Algorithm 2-screening:}

- A proper medical history, dental history and travel history should be required prior to clinically evaluating the patient as well as taking the patient's temperature.

- An example of a screening form that can be given to patients prior to a clinical exam has been included below.

- This screening questionnaire can be a reference point for dentists when determining patient treatment (Table 1).

- If a patient answers no to the first question, considerations can be made to postpone treatment.

- If a patient answers yes to any of the above questions (except the first), or presents with any of the symptoms mentioned above, it is recommended that non-emergent dental procedures be postponed for 2-3 weeks.

- However, if a patient has a dental complication that is potentially life-threatening, requires immediate treatment to stop ongoing tissue bleeding or alleviates severe pain or infection, the ADA recommends the patient must be seen as these are considered a dental emergency. 
Table 1 COVID-19 Screening Questionnaire (adapted)

\begin{tabular}{ll}
\hline Yes & COVID-19 screening question \\
\hline Urgent dental need question: Do you have uncontrolled dental or oral pain, \\
infection, swelling, bleeding, or trauma to your mouth? \\
Have you or anyone you live with tested positive for COVID-19? \\
In the past 14 days, have you or any household member had any contact with \\
a known COVID-19 patient? \\
Do you or any household member have symptoms over the past week: \\
-Loss of taste or smell \\
-Rashes on fingers or toes \\
-New difficulty breathing \\
-New cough \\
-Unusual fatigue \\
-Vomiting or diarrhea \\
-Loss of appetite? \\
Have you had any history of fever in the last 14 days of over $100.4 \mathrm{~F}$ or $38 \mathrm{C} ?$
\end{tabular}

\section{- Case selection: Algorithm 3-minimize COVID-19 transmission:}

- Procedures that do not generate aerosols may be performed safely with standard precautions.

- Procedures that generate aerosols create a risk to DHCP and patients and must be postponed unless equipped to perform procedures under airborne precautions (e.g. airborne infection isolation room (AIIR), N95 respirator, and other appropriate PPE). Otherwise, it is best to refer patients to facilities, such as hospitals, that are equipped to do so (Fig. 1).

- Tables 2 and 3 outline guidelines by both the American and Australian Dental Association for treating Dental Emergencies during the COVID-19 Pandemic.

\section{Materials and instruments}

- Standard precaution personal protective equipment (PPE) including: (Fig. 2)

- Gown

- Mask-level 3 (surgical mask)

- Eyewear with side shield protection, Face Shield

- Gloves

- Bouffant cap

- If performing a procedure that produces aerosol or in populations where the rate of COVID 19 infection is high in the population, the following PPE is recommended.

- Respirator: N95 or equivalent

- Rubber dam and high-volume evacuation 


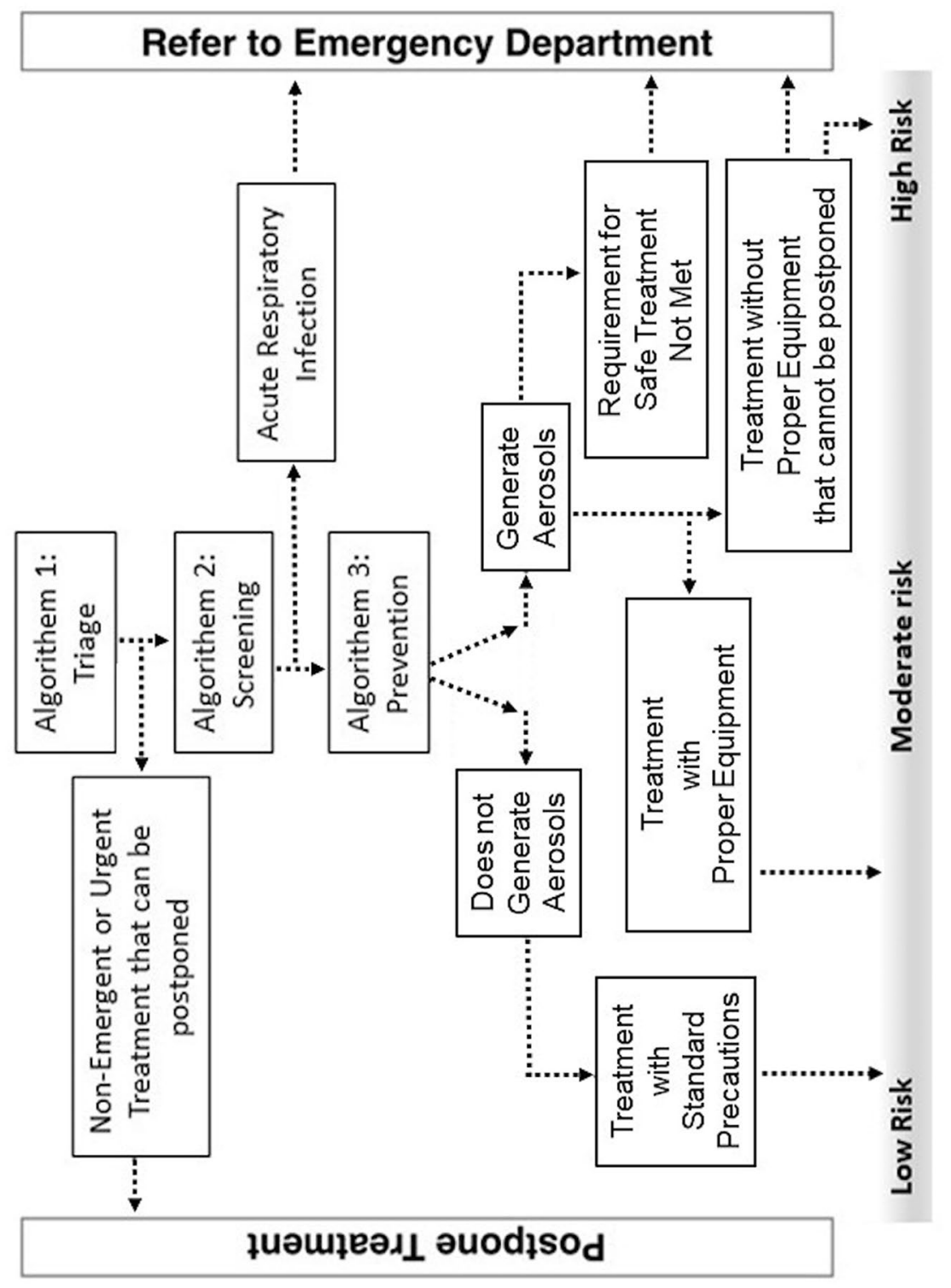

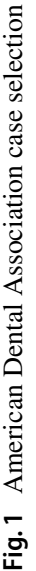


Table 2 American Dental Association (ADA) guidelines for treating dental emergencies

Dental complications Symptoms and procedures

\section{Emergencies}

- Potentially life-threatening

- Require immediate treatment to stop

- Ongoing tissue bleeding

- Alleviate severe pain

- Alleviate severe infection

\section{Urgencies}

- Management of conditions that require immediate attention to relieve severe pain and/or risk of infection and to alleviate the burden on hospital emergency departments

- Treat as minimally invasively as possible
- Uncontrolled bleeding

- Cellulitis or diffuse soft-tissue bacterial infection with intraoral or extraoral swelling that potentially compromises patient's airway

- Trauma involving facial bones, potentially compromising patient's airway

- Severe dental pain from pulpal inflammation

- Pericoronitis or third-molar pain

- Surgical post-operative osteitis, dry socket dressing changes

- Abscess, or localized bacterial infection resulting in localized pain and swelling

- Tooth fracture resulting in pain or causing soft tissue trauma

- Dental trauma with avulsion/luxation

- Dental treatment required prior to critical medical procedures

- Final crown/bridge cementation if the temporary restoration is lost, broken, or causing gingival irritation

- Biopsy of abnormal tissue

- Extensive dental caries or defective restorations causing pain

- Manage with interim restorative techniques when possible (SDF, glass ionomer)

- Suture removal

- Denture adjustment on radiation/oncology patients

- Denture adjustments or repairs when function impeded

- Replacing temporary fillings on endo access opening in patients experiencing pain

- Snipping or adjusting of an orthodontic wire or appliances piercing or ulcerating the oral mucosa

\section{Dental non-emergency}

\section{Routine or non-urgency}

- Initial or periodic oral examinations, recall visits, routine radiographs

- Routine dental cleaning and preventative therapies

- Orthodontic procedures other than those to address acute issues (e.g. pain, infection, trauma) or other issues critically necessary to prevent harm to the patient

- Extraction of asymptomatic teeth

- Restorative dentistry including treatment of asymptomatic carious lesions

- Aesthetic dental procedures 


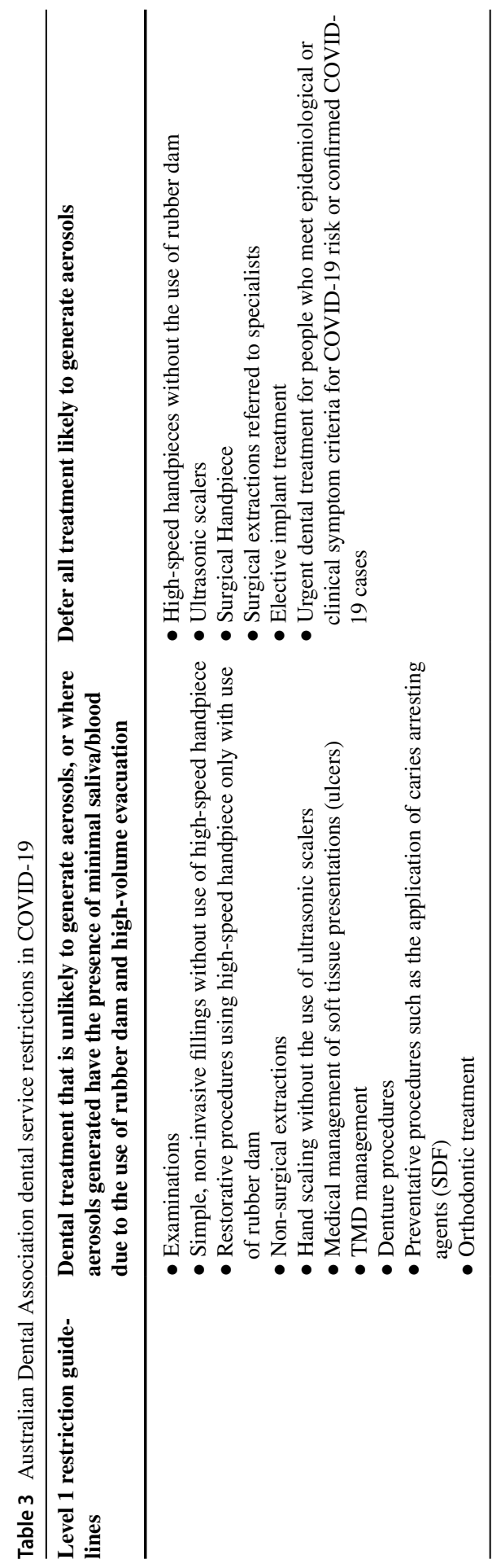




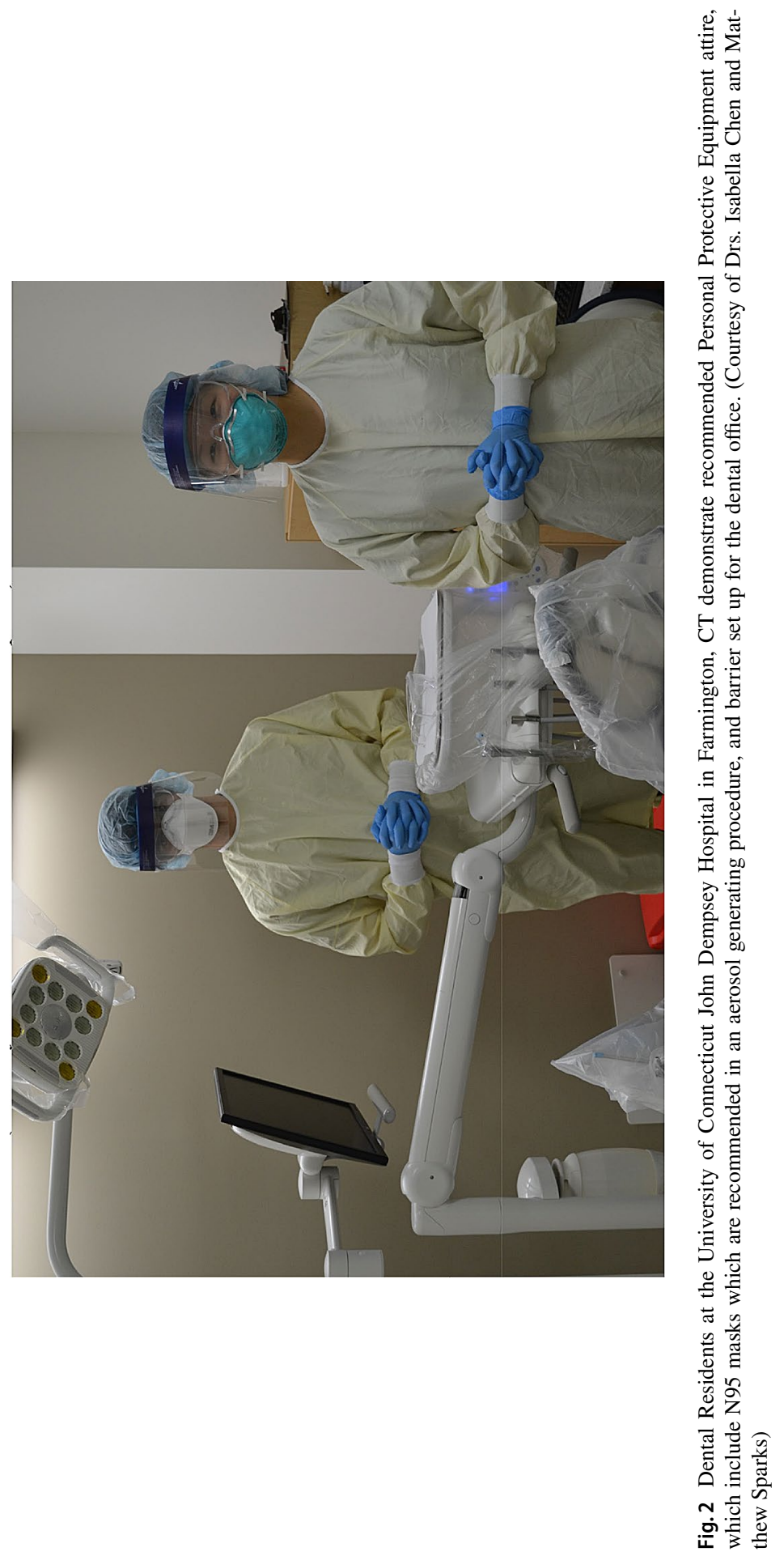




\section{Procedure}

As an Isolation precaution for all patients, patients must wear a facemask immediately as they enter the office, regardless if they are symptomatic or asymptomatic. For patients that are symptomatic, escort the patient to an isolated operatory to minimize spread of the virus. COVID-19 positive patients should be taken to an AIIR if available.

\section{During patient contact:}

- A protocol for PPE donning is recommended by the American Centers for Disease Control (CDC).

- Donning is done in this order: hand hygiene-full coverage gown-respirator (and mask over it)_face shield_-gloves

- Preprocedural mouth rinse $1.5 \%$ hydrogen peroxide or $0.2 \%$ povidone for $30 \mathrm{~s}$, two times.

- Chlorhexidine alone is not recommended

- Avoid/limit aerosol-generating procedures.

- If aerosols are to be produced, a N95 mask and full-face shield should be worn.

- If N95 masks are in short supply, the CDC has approved to wear a level 3 mask over the N95 mask to increase the life span.

- Rubber dam application to minimize droplet production.

- Use of 4-handed technique to control splash, splatter, and aerosols.

- Use of high-volume evacuators.

- Backflow can occur when using saliva ejector.

- Use of anti-retraction functions of handpieces may reduce cross-contamination.

- Minimize use of 3 in 1 syringe (air-water) that can generate droplets.

- If the patient is COVID-19 positive:

- Defer elective treatment for three weeks.

- If emergent care is indicated, the following must be executed.

- Negative pressure room.

- PPE, including use of N95 mask (per CDC guidelines).

- All other precautions are mentioned above.

\section{After patient contact:}

- PPE doffing 
- Doffing: remove soiled gloves and discard—remove face shield and place in receptacle for disinfecting - remove gown and place in laundry or dispose of disposable—remove mask—perform hand hygiene

- Handpieces disinfected according to manufacturer's instructions, as recommended by the CDC.

- Clean and heat sterilize handpieces that can be removed from the air lines and waterlines of dental units

- For handpieces that do not attach to air lines and waterlines, use FDA-cleared devices, and follow the validated manufacturer's instructions for reprocessing these devices.

- If a dental handpiece cannot be heat sterilized and does not have FDA clearance with validated instructions for reprocessing, do not use that device.

- Routine cleaning and disinfection procedures

- Hospital-grade disinfectant registered by the United States Environmental Protection Agency (EPA) are appropriate for COVID-19. Website: https:// www.epa.gov/pesticide-registration/list-n-disinfectants-coronavirus-covid-19.

- Include frequent cleaning of door handles, chairs, desks, bathrooms, elevators, and other frequently touched surfaces

- Hand hygiene

- Plain soap and water (cold or warm)

- Wet hands with clean, running water, and apply soap.

- Lather soap between hands, ensuring coverage of the backs of your hands, between your fingers, and under the nails.

- Scrub your hands together for at least $20 \mathrm{~s}$.

- Rinse your hands under clean, running water.

- Dry your hands by air drying or using a clean towel or paper towel.

- Antimicrobial soap and water

- Instructions for plain soap and water apply here as well.

- Alcohol-based hand rub with alcohol concentration of 70-90\%

- Per the CDC, alcohol-based hand rubs are more effective at killing bacteria and viruses. However, if hands are visibly soiled, soap and water must be used.

- If using lotion, use a water-based lotion, as petroleum-based lotions have been shown to weaken the properties of gloves.

- DHCPs should change from scrubs to personal clothing before returning home. Upon arriving home, DHCPs should take off shoes, remove and wash clothing (separately from other household residents), and immediately shower. 
Table 4 Differential diagnosis between COVID-19 and similar illnesses

\begin{tabular}{|c|c|c|}
\hline & Primary symptoms & $\begin{array}{l}\text { Less frequent Symp- } \\
\text { toms }\end{array}$ \\
\hline COVID-19 & $\begin{array}{l}\text { - Fever } \\
\text { - Dry cough } \\
\text { - Shortness of breath (if severe) } \\
\text { - Fatigue }\end{array}$ & $\begin{array}{l}\text { - Diarrhea } \\
\text { - Aches and pains } \\
\text { - Nasal congestion } \\
\text { - Runny nose } \\
\text { - Sore throat } \\
\text { - Rash }\end{array}$ \\
\hline Seasonal flu (influenza) & $\begin{array}{l}\text { - Fever or chills } \\
\text { - Cough } \\
\text { - Muscles or body aches } \\
\text { - Headache } \\
\text { - Fatigue }\end{array}$ & $\begin{array}{l}\text { - Sneezing } \\
\text { - Sore throat } \\
\text { - Runny or stuffy nose } \\
\text { - Nausea } \\
\text { - Diarrhea (rare) }\end{array}$ \\
\hline $\begin{array}{l}\text { Common cold or upper respiratory } \\
\text { infection }\end{array}$ & $\begin{array}{l}\text { - Sneezing } \\
\text { - Stuffy or runny nose } \\
\text { - Sore throat } \\
\text { - Chest discomfort }\end{array}$ & $\begin{array}{l}\text { - Fatigue } \\
\text { - Body aches (rare) }\end{array}$ \\
\hline Seasonal allergies or hay fever & $\begin{array}{l}\text { - Stuffy or runny nose } \\
\text { - Itchy eyes/mouth/skin } \\
\text { - Sneezing }\end{array}$ & $\begin{array}{l}\text { - Wheezing } \\
\text { - Shortness of breath } \\
\text { - Fatigue }\end{array}$ \\
\hline
\end{tabular}

\section{Differential diagnosis}

There are some similarities between COVID-19 symptoms and other upper respiratory illnesses. It is critical that until a patient is tested and diagnosed with COVID19, individuals who present with such symptoms should be kept in quarantine to prevent spread. These are outlined in Table 4.

\section{Pitfalls and complications}

Due to the nature of the virus, and not being able to determine if an individual is COVID-19 positive but asymptomatic or pre-symptomatic, dental professionals could be exposed to the virus without knowing. A question that many dental professionals have is what steps need to be taken if they unknowingly treated a COVID-19 positive patient. The World Health Organization (WHO) has reported guidelines to follow if and when health care workers (HCW) have been exposed to the COVID-19 virus. The management of HCW exposed to COVID-19 varies according to the risk categorization.

- Recommendations for HCWs at high risk of exposure (see Fig. 1):

- Stop all health care interactions with patients for a period of 14 days after the last day of exposure to a confirmed COVID-19 patient.

- Be tested for COVID-19. 
- Quarantine for 14 days in a designated setting.

- Health care facilities should:

- Provide psychosocial support to HCW during quarantine, or throughout the duration of illness if HCW is confirmed to have COVID-19.

- Provide compensation for the period of quarantine and for the duration of illness (if not on a monthly salary) or contract extension for the duration of quarantine/illness.

- Provide a review of infection protection and control training for the health care facility staff, including HCWs at high risk for infection after a 14-day quarantine period.

- Recommendations for health workers at low risk of exposure (see Fig. 1):

- Self-monitor temperature and respiratory symptoms daily for 14 days after the last day of exposure to a COVID-19 patient.

- HCWs should call the health care facility if they develop any symptoms suggestive of COVID-19.

- Reinforce contact and droplet precautions when caring for all patients with acute respiratory illness and standard precautions for all patients

- Reinforce airborne precautions for aerosol-generating procedures on all suspected and confirmed COVID-19 patients.

- Reinforce the rational, correct, and consistent use of personal protective equipment.

- Apply WHO's "My 5 Moments for Hand Hygiene" before touching a patient, before any clean or aseptic procedure, after exposure to body fluid, or touching a patient, and after touching a patient's surroundings.

- Practice respiratory etiquette at all times.

Funding No funding was obtained for this article.

\section{Compliance with ethical standards}

Conflict of interest No conflicts of interest to declare with the writing of this article.

\section{Further reading}

1. Coronavirus disease (COVID-19) Pandemic. (n.d.). https://www.who.int/emergencies/diseases/novel -coronavirus-2019. Retrieved 5 May 2020

2. Ather A, Patel B, Ruparel NB, Diogenes A, Hargreaves KM (2020) Coronavirus disease 19(COVID-19): implications for clinical dental care. J Endod 46(5):584-595. https://doi.org/10.1016/j.joen.2020.03.008

3. Hoffmann M, Kleine-Weber H, Schroeder S, Krüger N, Herrler T, Erichsen S, Pöhlmann S (2020) SARSCoV-2 cell entry depends on ACE2 and TMPRSS2 and is blocked by a clinically proven protease inhibitor. Cell. https://doi.org/10.1016/j.cell.2020.02.052

4. American Dental Association. Interim guidance for minimizing risk of COVID-19 transmission. https ://www.ada.org/ /media/CPS/Files/COVID/ADA_COVID_Int_Guidance_Treat_Pts.pdf?utm_sourc e=adaorg\&utm_medium=covid-statement-200401\&utm_content=cv-pm-ebd-interim-response\&utm_ campaign $=$ covid -19 . Retrieved 8 May 2020 
5. General Dental Council (2020) High level principles for good practice in remote consultations and prescribing. https://www.gdc-uk.org/docs/default-source/guidance-documents/high-level-principles-remot e-consultations-and-prescribing.pdf. Retrieved 8 May 2020

6. ADA Interim Guidance for Management of Emergency and Urgent Dental Care. https://www.ada.org/ / media/CPS/Files/COVID/ADA_Int_Guidance_Mgmt_Emerg-Urg_Dental_COVID19.pdf?utm_sourc e=cpsorg\&utm_medium =cpsalertbar\&utm_content=cv-pm-ebd-interim-flowchart\&utm_campa ign=covid-19

7. PPE Sequence (2020). https://www.cdc.gov/hai/pdfs/ppe/PPE-Sequence.pdf

8. Protecting Healthcare Personnel (2014). https://www.cdc.gov/hai/prevent/ppe.html. Retrieved 2020

9. ADA-what constitutes a dental emergency?(2020). https://success.ada.org/ /media/CPS/Files/OpenFiles/ ADA_COVID19_Dental_Emergency_DDS.pdf. Retrieved 10 Apr 2020

10. Curley B (2020) Different symptoms for coronavirus, flu, and allergies. https://www.healthline.com/ health-news/flu-allergies-coronavirus-different-symptoms. Retrieved 30 Apr 2020

11. Health Workers (2020). https://www.who.int/emergencies/diseases/novel-coronavirus-2019/technicalguidance/health-workers. Retrieved 20 Apr 2020

12. List N: disinfectants for use against SARS-CoV-2 (2020). https://www.epa.gov/pesticide-registration/ list-n-disinfectants-use-against-sars-cov-2. Retrieved 30 Apr 2020

13. Dental Settings (2020). https://www.cdc.gov/coronavirus/2019-ncov/hcp/dental-settings.html. Retrieved 5 May 2020

14. Fang L, Karakiulakis G, Roth M (2020) Are patients with hypertension and diabetes mellitus at increased risk for COVID-19 infection? Lancet Respir Med https://doi.org/10.1016/s2213 $-2600(20) 30116-8$

15. Godoy M (2020) Concerned about taking Ibuprofen for coronavirus symptoms? Here's what experts say. https://www.npr.org/sections/health-shots/2020/03/18/818026613/advice-from-france-to-avoid -ibuprofen-for-covid-19-leaves-experts-baffled. Retrieved 24 Mar 2020

16. Center for Drug Evaluation and Research (2020) FDA advises patients on use of NSAIDs for COVID19. https://www.fda.gov/drugs/drug-safety-and-availability/fda-advises-patients-use-non-steroidal-antiinflammatory-drugs-nsaids-covid-19. Retrieved 24 Mar 2020

17. The Australian Dental Association (2020). https://www.ada.org.au/Covid-19-Portal/Cards/Dental-Profe sionals/Guidelines-and-Risk-Factors/Practical-Advice-for-stepping-back-to-Level-2-Rest. Retrieved 3 May 2020

18. Hallier C, Williams DW, Potts AJ, Lewis MA (2010) A pilot study of bioaerosol reduction using an air cleaning system during dental procedures. Br Dent J 209(8):E14

19. Wooley A (2020) How to protect against transmission risks in dental offices during COVD-19. https:// enviroklenz.com/transmission-risks-in-dental-offices-covid-19/. Retrieved 30 Apr 2020

20. US Department of Labor Occupational Safety and Health Administration, Guidance on Preparing Workplaces for COVID-19 (2020). https://www.osha.gov/Publications/OSHA3990.pdf

21. Infection Control: Severe acute respiratory syndrome coronavirus 2 (SARS-CoV-2) (2020). https:// www.cdc.gov/coronavirus/2019-ncov/hcp/infection-control-recommendations.html. Retrieved 3 May 2020

22. Dexter F, Parra MC, Brown JR, Loftus RW (2020) Perioperative COVID-19 defense: an evidencebased approach for optimization of infection control and operating room management. https://www. ncbi.nlm.nih.gov/pubmed/32217947/. Retrieved 5 May 2020

23. Darnell ME, Taylor DR (2006) Evaluation of inactivation methods for severe acute respiratory syndrome coronavirus in noncellular blood products. Transfusion 46(10):1770-1777. https://doi.org/10.11 11/j.1537-2995.2006.00976.x

24. Roopinder T (2020) Does UV kill the coronavirus? Here's what we know. https://new.engineering.com/ story/does-uv-kill-the-coronavirus-heres-what-we-know. Retrieved 5 May 2020

25. Consejo General de Colegios de Odontólogos y Estomatólogos de España. Plan estratégico de acción para clínicas dentales durante el periodo de desescalada. https://www.consejodentistas.es/comunicaci on/actualidad-consejo/notas-de-prensa-consejo/item/1783-plan-estrategico-de-accion-para-clinicasdentales-durante-el-periodo-de-desescalada.html. Retrieved 8 May 2020

26. Wu Y et al (2020) Nervous system involvement after Infection with Covid19. Brain Behav Immun. https://doi.org/10.1016/j.bbi.2020.03.031 (Accessed 28 May 2020)

Publisher's Note Springer Nature remains neutral with regard to jurisdictional claims in published maps and institutional affiliations. 